\title{
Medios y poder: 1984
}

\section{Gruber, Mónica [ver currículum del autor, docente de la Facultad de Diseño y Comunicación]}

Resumen: La II Guerra Mundial, la Shoah, el Gulag, Hiroshima y Nagasaki, constituyen un largo listado de hechos ignominiosos que han marcado a fuego a la humanidad. No en vano, lúcidos intelectuales y artistas alzaron sus voces para señalar el fracaso de los antiguos paradigmas racionales que sustentaron el modernismo: si ese racionalismo había conducido al fracaso, había que buscar nuevas estructuras que ayudasen a superar el pasado. Es así que avizoraron una esperanza en el resurgimiento del mito.

Con la posguerra, se abrió una etapa conocida como la Guerra Fría, que se caracterizó, entre otras cosas, por el vertiginoso crecimiento comunicacional, así como por el desarrollo de todo tipo de mecanismos

Cuadernos del Centro de Estudios de Diseño y Comunicación Nº 68

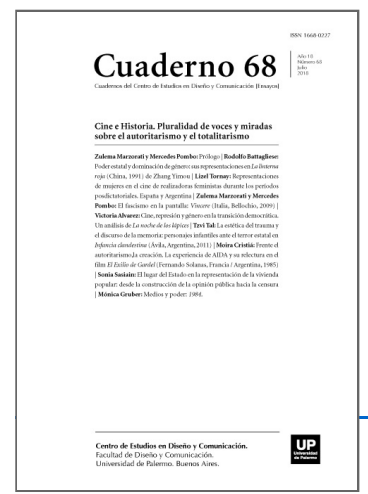

ISSN: 1668-0227

Cine e Historia.

Pluralidad de voces y

miradas sobre el

autoritarismo y el

totalitarismo

Año XVIII, Julio 2018, Buenos Aires, Argentina | 148 páginas

descargar PDF ver índice de la publicación

Ver todos los libros de la publicación

compartir en Facebook

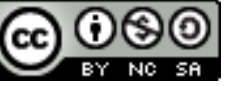

Esta obra está bajo una Licencia Creative

Commons Atribución-NoComercial-

Compartirlgual 4.0 Internacional de control y gadgets que abarcaron

desde microfilms y micrófonos, hasta cámaras. La URSS y los EEUU, con sus servicios secretos jugaron una guerra de nervios donde todo parecía válido: suero de la verdad, torturas diversas y lavado de cerebros, entre otros, fueron términos que se trasladaron desde el campo político a la literatura, el cine y el teatro. Dichos elementos abonaron la imaginación de los artistas, que en casos como el que analizamos situaron en un futuro distópico las críticas al mundo que les rodeaba.

El presente trabajo se propone analizar algunos aspectos de la novela 1984 de George Orwell (1948), explorando las líneas de profundidad hermenéutica que dieron vida a sus personajes y conflictos, para luego abordar la transposición cinematográfica homónima. Al comparar la relación entre los medios de comunicación y el poder -un aspecto fundamental tanto en el texto literario con su incidencia en el audiovisual- sostenemos que así como la vida de los ciudadanos en la novela es totalmente controlada por los agentes de poder, esto vuelve a quedar en evidencia en la película del mismo nombre filmada en el año 1984, situación que también se extiende hasta hoy. Muy a nuestro pesar, los totalitarismos continúan vigentes en la actualidad.

Palabras clave: Guerra Fría - totalitarismos - Orwell - 1984 - Representaciones fílmicas. 
(*) Licenciada y Profesora en Artes de la U.B.A. donde se desempeña como J.T.P. y Ayudante Regular de T.P. en La Literatura en las Artes Combinadas I. Profesora de Arte y Literatura (en la UMSA), del Seminario de Medios de Comunicación (UTN), de Discurso Audiovisual II (Historia del Cine, en la UP).

Introducción

George Orwell fue el pseudónimo que adoptó Eric Arthur Blair (1903-1950), escritor y periodista inglés, autor de 1984, una de las grandes creaciones literarias del mundo contemporáneo. Se desempeñó como funcionario policial de la corona británica en las colonias; su trabajo en Birmania lo llevó a tomar contacto con situaciones de injusticia y maltrato hacia los pobladores de dichos territorios, desarrollando un fuerte sentimiento antiimperialista que lo llevaría, finalmente, a renunciar a su labor. Como resultado de este desencanto, algunas de las novelas del primer período de su carrera se centraron en la exposición de dichas problemáticas. El regreso a su país lo llevó a vivenciar circunstancias poco agradables: hombres degradados por el desempleo, el hambre y la falta de hogar, abonando de este modo el terreno en el que crecerían sus nuevas denuncias.

Fue partícipe activo de la Guerra Civil Española, así como muchas figuras relevantes del ámbito artístico internacional. Descolló rápidamente por su labor comprometida en el entrenamiento de las fuerzas antifranquistas. Ante la desaparición de Andreu Nin, líder del POUM1 y, dado que se trataba de un célebre participante en dicha contienda, esto lo convirtió en un blanco potencial de la Falange. El POUM fue declarado ilegal, muchos de sus miembros fueron ejecutados mientras que otros eran encerrados y torturados como su amigo Georges Kopp, a quien trataría -arriesgando de su propia vida- de liberar. El peligro era mayor cada día, su renombre que lo convertía en un codiciado blanco de las fuerzas franquistas, situación por la cual le recomendaron abandonar España. Él lo vivió como una huida poco digna. La Segunda Guerra y sus avatares no dejarían de sacudirlo e indignarlo. A partir de allí, su cruzada se centró en denunciar al nacionalsocialismo y al estalinismo.

De su pluma nacieron obras como Sin blanca en París y Londres (1933), Los días de Birmania (1934), Homenaje a Cataluña (1938), Rebelión en la granja (1945) y Mil novecientos ochenta y cuatro (1948), entre otros.

Orwell, el Hermano Grande y su mundo poco feliz

Corre el año mil novecientos ochenta y cuatro. El mundo se ha visto sacudido por cruentas guerras y ha sido devastado por el estallido de las bombas nucleares. Todo ha cambiado, incluso la geografía del mismo. Los países han desaparecido. Como en un tablero de TEG2, el mundo está conformado por tres grandes continentes: Oceanía, Eurasia y Asia Oriental, gobernados por oligarquías totalitarias en guerra constante.

El terror se ha instalado en la vida cotidiana de los ciudadanos. Londres, "es la capital de la Pista de Aterrizaje Uno y tercera ciudad de Oceanía por su población” (Orwell, 1950, p. 10). Este es el mundo pesimista que pergeña George Orwell para 1984. Dicha novela constituye junto con Un mundo feliz de Aldous Huxley y Fahrenheit 451 de Ray Bradbury, una de las tres grandes utopías3 de la literatura contemporánea. Dentro de dicha clasificación nos situamos en el terreno de las distopías4. Si bien se halla circunscripta al género de ciencia ficción, el autor ha introducido además elementos propios del realismo y de la parodia. 
La libertad es esclavitud

La ignorancia es fuerza

El lema del INSOC5 no puede menos que sacudirnos por las contradicciones que presenta, a modo de oxímoron6 .

Para que nadie pueda articular un pensamiento contrario al régimen se ha creado una nueva lengua, cuyo vocabulario se halla actualizado en la Decimoprimera Edición del Diccionario de Neohabla. El Apéndice de la novela da una idea cabal de su funcionamiento. Allí puede leerse cómo se han eliminado palabras, en especial los adjetivos y otros conceptos innecesarios, simplificado al extremo la terminología. Se ha implementado, de este modo, una especie de lenguaje objeto. De este modo Syme, uno de los responsables de la elaboración de dicho diccionario, lo manifiesta en el relato: "terminaremos por hacer literalmente imposible el delito de pensamiento, porque no existirán vocablos para expresarlo". (Orwell, 1950, p. 69)

En la novela, Winston Smith, uno de los miembros del Partido, se atreve a desafiar el statu quo al escribir un diario íntimo con el objeto de dejar un testimonio a las futuras generaciones, denunciando lo que en verdad está sucediendo. Quizás nadie llegue a leerlo, pero para nuestro protagonista valdrá la pena intentarlo. Smith no viola ninguna ley establecida ya que escribe en una época en la cual nada está prohibido, pero todo constituye un delito punible y de ser descubierto: “...era casi seguro que sería castigado con la pena capital, o por lo menos, con veinticinco años de trabajos forzados en un campo de concentración". (Orwell, 1950, p. 14)

Nos iremos enterando de a poco de los detalles de la vida solitaria de Smith. Una ex esposa, que ignora si vive o no, adicta al pensamiento partidario. Los recuerdos de su niñez que por momentos lo atormentan, ya que se considera responsable de la muerte de su pequeña hermana. Su vida personal en el edificio Victory Mansions, quiénes son sus vecinos, entre ellos Parsons y su familia, cuyos hijos - unos verdaderos niños espías-se destacarán a lo largo del relato por delatar a cuanto adulto crean que conspira contra el Partido, incluidos sus padres. Se irá develando cuál es la labor cotidiana del protagonista en el Ministerio de la Verdad (Miniver), quiénes son sus compañeros de trabajo y su primer contacto con Julia, una joven, que trabaja en otra sección del edificio gubernamental, perteneciente a la Liga Juvenil Antisexual a quien considera inicialmente una espía del régimen, es decir, un policía del pensamiento. Pronto descubre que la muchacha en realidad está enamorada de él y Winston no tardará en corresponderla. El alquiler de un cuarto en el barrio proletario en la casa del señor Charrington, dueño del negocio de baratijas en el que tiempo atrás adquirió su diario íntimo, permite la realización de los encuentros clandestinos de la pareja. Estos momentos de intimidad, en los cuales son auténticos y expresan sus sentimientos, pensamientos y temores, darán las pautas precisas para la cristalización de su amor prohibido. El contacto con O'Brien, un directivo del INSOC, llevará a Winston y Julia a tomar contacto con el libro de Goldstein, el enemigo del Gran Hermano7 y autor del libro Teoría y práctica del constructivismo oligárquico. Sin embargo, no tardarán en caer en manos de la policía del pensamiento que ha seguido de cerca sus actividades. Engañados por quienes creían sus aliados, sólo le queda a la pareja esperar un rápido desenlace.

Al sórdido paisaje urbano, destruido, decadente, paupérrimo de una Inglaterra gris y sombría hay que agregar la omnipresencia de las imágenes mediáticas: vallas callejeras con la imagen del Big Brother, telepantallas en espacios públicos que transmiten permanentemente imágenes provenientes de los diversos frentes de batalla, 
pantallas televisivas en los hogares que cumplen idéntica función, además de ser simultáneamente cámaras, desde las cuales todos los miembros del partido son permanentemente vigilados (tal como señala el slogan del Partido: "El Hermano Grande os vigila").

El mundo que rodea a nuestro protagonista se presenta superpoblado de imágenes visuales y sonoras. De hecho, Orwell avizora un futuro cercano, concibiéndolo como un gran panóptico: un mecanismo donde el recluso se encuentra permanentemente escrutado. Uno de los dispositivos carcelarios más atroces ya que no sólo se halla privado de su libertad sino también de su privacidad8 .

Del mismo modo, dichas pantallas no sólo son capaces de emitir la información que difunde el INSOC, sino que cumplen la tarea de ser cámaras de vigilancia. La descripción suministrada por el autor parece tomada de la planificación carcelaria propuesta por Bentham, de hecho, al describir su apartamento Winston señalaba: "Mientras permaneciera dentro del campo visual de la placa metálica, podía ser visto a la vez que oído. Desde luego, no existía medio de comprobar en un momento dado si era uno objeto de vigilancia o no..." (Orwell, 1950, p. 9)

Sin embargo, determinados miembros del partido, aquellos que conforman la élite, tienen la prerrogativa de apagar momentáneamente las telepantallas, hecho que Winston podrá comprobar -un tanto sorprendidocuando visite a O'Brien en su hogar.

Algunas preguntas son inevitables a la hora de enfrentarnos al relato: ¿Cómo puede una sociedad aceptar pasivamente lo que ocurre? ¿Cómo se sustenta un totalitarismo de este tipo? ¿Cómo pudo vislumbrar Orwell este futuro tan pesimista y aterrador?

En la novela, las clases medias forman parte del INSOC, de hecho, son responsables de diversas acciones que abarcan todos los matices del odio: desde torturas hasta delaciones. Creemos que la permanente amenaza de la guerra, ora con Eurasia, ora con Asia Oriental, pone de manifiesto una precaria paz y una crisis permanente que propicia un contexto perfecto para activar resentimientos sociales, convirtiéndolos en chivos expiatorios del régimen. Ello se hará evidente por ejemplo en los Dos Minutos de Odio, en la Semana del Odio y en las ejecuciones públicas.

Los miembros del partido observan y toman parte en la punición, a partir de las silbatinas e insultos, ya que también la exposición del culpable de este modo formaba parte de las escenas de suplicio descriptas.

La delación se transforma en moneda corriente debido a la atomización de poder, del mismo modo que señalamos en otro lugar (Gruber, 2011), al analizar la sociedad descripta por Ray Bradbury en Fahrenheit 451. Recordemos lo que le señala Parsons -su vecino y compañero de trabajo- al protagonista en el momento en que ambos están detenidos:

-¿Quién lo delató? -dijo Winston.

-Mi hija -respondió Parsons con una especie de cerrado orgullo-. Estaba escuchando por el ojo de la cerradura: oyó lo que dije y al día siguiente dio parte a la patrulla: no está mal para una chiquilla de siete años ¿eh? Y no crea que por eso le guardo rencor. Al contrario, me siento orgulloso de ella. Demuestra que, por lo menos, la he sabido educar. (Orwell, 1950, p. 280) 
Esto nos lleva a relacionarlo con la preocupación de intelectuales provenientes del campo de las ciencias sociales que abordaron estudios sobre el nacionalsocialismo, entre ellos Michel Foucault quien, en su Genealogía del racismo, reflexiona sobre el tema enfatizando: "En el Estado nazi todos tenían derecho de vida y muerte sobre su propio vecino, aunque no más fuera que a través de la práctica de la denuncia, que permite suprimir, o hacer suprimir, al que está al lado". (Foucault, 1993, p. 185)

Ello explica, por qué un hijo era capaz de delatar a su padre, un padre a su hijo, a un familiar, a un vecino o a un amigo. La disolución de ciertos lazos afectivos juega una parte importante en este tipo de estado. En nuestro caso, Winston escribe en su diario:

Suprimir por completo la familia no habría sido recomendable; antes bien, se estimulaba el amor a los hijos casi conforme a la vieja usanza. Pero, a renglón seguido, se inculcaba a los niños el antagonismo hacia sus padres, incitándolos a espiarlos y denunciarlos. En realidad, la familia pasaba a ser de ese modo una prolongación de la Policía del pensamiento. (Orwell, 1950, p. 162)

Lo señalado juega un rol fundamental en la re-producción de esta sociedad y el mantenimiento del statu quo. Al leer las palabras de nuestro protagonista es inevitable pensar en que, en el Estado Nazi, la familia funcionaba del mismo modo.

En la novela de G. Orwell asistimos con estupor a la Semana del Odio o a los Dos Minutos de Odio, donde las actividades cotidianas son interrumpidas para dar libertad a ese sentimiento en actos colectivos donde lo primitivo aflora en el grupo. La imagen del chivo expiatorio se hace presente en las telepantallas.

Esa violencia se halla extendida en la sociedad orwelliana, es una práctica generalizada, llevada a cabo por todos y cada uno de los miembros del Partido. Esto se pone de manifiesto en boca del protagonista ya que sus sentimientos iniciales hacia Julia poseen una alta dosis de violencia contenida: "Tentadoras ansias cruzaron por su imaginación como un haz de luz. Se imaginaba golpeándola con una cachiporra de goma hasta dejarla sin vida. Le agradaría amarrarla a una estaca y acribillarla a flechazos como a San Sebastián”. (Orwell, 1950, p. 24)

Marta Tafalla profundiza acerca del modo en que el nazi, disfrutaba de su poder sobre la vida y la muerte: "El nazi goza de la vida decidiendo sobre la muerte de los demás..." (Tafalla, 2003, p. 9). Volviendo a la novela, los miembros del INSOC delatan, torturan, son testigos de ajusticiamientos, piden a gritos la muerte los traidores. De este modo, las ejecuciones colectivas son convertidas en espectáculos para las masas.

Esto no es novedoso, Foucault al referirse a los suplicios medievales señala el rol del público:

En esta escena de terror, el papel del pueblo es ambiguo. Se le llama como espectador; se le convoca para que asista a las exposiciones, a las retractaciones públicas; las picotas, las horcas y los patíbulos se elevan en las plazas públicas y al borde de los caminos; [...]. Es preciso no sólo que la gente sepa, sino que vea por sus propios ojos. Porque es preciso que se atemorice; pero también porque el pueblo debe ser el testigo, como el fiador del castigo, y porque debe hasta cierto punto tomar parte en él. (Foucault, 2004, p. 63)

Orwell había presenciado en 1937 el intento de golpe comunista en Barcelona. Christopher Hitchens nos señala: "El líder catalán Andreu Nin, fundador del POUM, fue secuestrado, salvajemente torturado y -como se negó a quebrarse-, asesinado. Luego los portavoces comunistas declararon que se había escapado para unirse a los 
nazis". (Hitchens, 2002, p. 78) ¿No resuenan acaso estos hechos tras la novela del autor de Homenaje a Cataluña?

La modificación de la memoria en 1984 se transforma en el arma primordial. Los medios constituyen la quintaesencia del régimen, de hecho, el Ministerio de la Verdad es el "que se dedicaba a las noticias, a los espectáculos, la educación y las bellas artes" (Orwell, 1950, p. 11). El Miniver, en realidad es el que dirige este maquiavélico mecanismo para modificar la verdad. Verdad que en realidad no existe porque se ha perdido entre tantas mentiras y cambios: el personal de dicha dependencia gubernamental concreta esto, y las pruebas de lo fraguado son rápidamente destruidas para que no sea posible en el futuro probar que ha existido dicha manipulación. De este modo, la historia como documento no existe, sino que va modificándose permanentemente de acuerdo a las necesidades del Partido. La alteración alcanza los periódicos, libros y panfletos. El fuego sirve para destruir las evidencias al tiempo que se fabrica la información que la reemplaza, en un proceso que parece no tener fin; de este modo libros, diarios y todo tipo de impresos son reescritos y quemados en hornos ocultos. De eso se trata la labor cotidiana de nuestro protagonista. Recibir una orden escrita, la indicación de un determinado periódico, la nota a modificar, el quemado posterior de la edición modificada. De este modo: "Día a día, y bien pudiera afirmarse minuto a minuto, se actualizaba el pasado". (Orwell, 1950, p. 54)

De la realidad a la ficción y viceversa

Luego de una pormenorizada lectura de la novela no nos quedan dudas de que Orwell denuncia su temor al estalinismo y al nacionalsocialismo.

Conocedor de los sórdidos detalles de los hechos infames acaecidos durante la última Guerra Mundial, se hace eco de todo ello en sus páginas. Mencionaremos a continuación algunas relaciones de las múltiples que podemos encontrar.

La primera que nos viene a la mente es el funcionamiento de Alemania y la deificación de un líder de autoridad omnímoda y patriarcal como Adolf Hitler. Nos basta seguir su presencia en los actos públicos y su estudiado manejo del fervor de las masas para notar cómo arengaba al público para que exteriorizasen su odio hacia los judíos. De este modo, se responsabilizaba a aquellos de la crisis que atravesaba el país, entre otras cosas. En el relato orwelliano, Goldstein y los miembros de la hermandad, así como los plebeyos serán los chivos expiatorios del Régimen.

Numerosos testimonios han dado cuenta de la sistemática destrucción de libros9 a lo largo de la historia de la humanidad. Fernando Báez al referirse a la quema de libros señala: "Al destruir con el fuego, el hombre juega a ser Dios, dueño del fuego de la vida y de la muerte" (Báez, 2005, p. 24). Acaso eliminar de los registros a algún miembro del partido, no dejar huellas de su existencia, ¿no es un modo de jugar con esa omnipotencia? ¿No es un modo de jugar a ser Dios?

El tema de la represión y prohibición de la lectura como producto de los regímenes totalitarios ha sido ampliamente trabajado en el ámbito del ensayo; Alberto Manguel en La biblioteca de noche reflexiona refiriéndose a los libros y los campos de exterminio, en el capítulo titulado "La biblioteca como supervivencia": 
“...Leer y el ritual de la lectura se convirtieron en actos de resistencia: como observó el psicólogo italiano Andrea Devoto, 'todo podía considerarse como resistencia porque todo estaba prohibido'”. (Manguel, 2007, p. 241)

Uno de los pilares del nazismo lo constituyó, indudablemente, la construcción de la ideología que lo sustentaba. De este modo, se manipuló la opinión pública, se atomizó el poder haciéndoles creer que todos y cada uno de los integrantes del pueblo alemán eran custodios del régimen, lo cual habilitaba las delaciones aun en el seno familiar. Los jóvenes eran adoctrinados ideológica y físicamente en organizaciones militares como las Juventudes Hitlerianas, se fomentó el deporte y la búsqueda de la perfección del cuerpo. Se creó todo un vocabulario para referirse a los judíos y la famosa solución final para no dejar rastros visibles del verdadero significado de este macabro operativo. Mientras tanto, se responsabilizó a los judíos (Di Tella et al, 2008, p. 501) de todos los males que aquejaban a Alemania, pauperizando su condición. Si no era considerado humano entonces, el exterminio y el expolio de sus pertenencias estaba justificado. Despojados del nombre que los identificaba, dejaban de ser sujetos para convertirse en un número dentro de un campo de concentración.

Ello no resulta novedoso, Germani en su aproximación al autoritarismo destaca:

El resentimiento se expresa en sí mismo como 'una tendencia desinteresada para infligir castigo' y ha sido siempre especialmente fuerte en aquella clase social que puede definirse vagamente como pequeña burguesía o clase media baja. El resentimiento se relaciona con las presiones, con los grupos de referencia conflictivos, con sentimientos de inferioridad y con la inseguridad básica originada en la posición intermedia de esos estratos sociales. Aunque el resentimiento y su expresión son endémicos de las posiciones de la clase media baja, pueden ser activados en gran parte en momentos de crisis. (Germani, 2003, p. 77)

Doob (1979) en su exhaustivo análisis de las características de la propaganda nazi, explica la metodología implementada por el Ministro Joseph Goebbels. Algunos de los tópicos son aplicables a nuestro análisis de Mil novecientos ochenta y cuatro. Iremos citando aquellos que consideramos pertinentes y traspolándolos al caso al que nos convoca:

1. "Los propagandistas deben tener acceso a la información referente a los acontecimientos y a la opinión pública" (Doob, 1979, p. 384), de hecho, Winston trabaja con los periódicos y son los empleados del Miniver quienes tienen acceso a dicha información y la modifican de acuerdo a las órdenes y requerimientos.

2. "La propaganda debe ser planeada y ejecutada por una sola autoridad" (Doob, 1979, p. 385). En nuestro caso, el Ministerio de la Verdad tiene a cargo estas funciones.

3. "Para ser percibida, la propaganda debe suscitar el interés de la audiencia y debe ser transmitida a través de un medio de comunicación que llame poderosamente la atención" (Doob, 1979, p. 388). En la novela las telepantallas que transmiten en forma continua a lo largo de las veinticuatro horas del día, captan la atención del público televidente debido a la fascinación que provoca la imagen en movimiento; la presencia de ellas en pasillos, residencias familiares, calles y ámbitos laborales, nos demuestran la pregnancia del medio emisor.

4. "Sólo la credibilidad debe determinar si los materiales de la propaganda han de ser ciertos o falsos" (Doob, 1979, p. 390). El Ministro de Propaganda nazi basaba su política en el manejo estratégico de la verdad y la mentira. En los diarios sostenía a rajatabla que el que utilizaba los embustes era el enemigo. Goebbels 
asimismo esgrimía la verdad sólo en aquellos casos en los que se pudiese, más tarde, probar que eran mentiras. "Por consiguiente las mentiras eran útiles cuando no podían ser desmentidas." Siguiendo esta línea de pensamiento nos damos cuenta de que, en el Miniver, la verdad se maneja a discreción siguiendo este esquema, el caso en el cual se pone de manifiesto es el de la modificación de la ración semanal de chocolate.

5. "El material de propaganda puede ser utilizado en operaciones cuando ayude a disminuir el prestigio de ese enemigo, o preste apoyo al propio objetivo del propagandista" (Doob, 1979, p. 3894). En nuestro caso cuando el supuesto "enemigo del INSOC" es quebrado luego de las torturas a las que es sometido, éste es capaz de confesar lo que el victimario desea, por lo tanto, la confesión pública de los crímenes que supuestamente ha cometido se televisa permanentemente como amenaza a futuros sediciosos.

6. "La propaganda debe etiquetar los acontecimientos y las personas con frases o consignas distintivas" (Doob, 1979, p. 397). Los acontecimientos relativos al campo de batalla, las frases de los oradores del partido, las de Goldstein, sirven al régimen para identificar acontecimientos, ideas, etc.

7. "La propaganda debe facilitar el desplazamiento de la agresión, especificando los objetivos para el odio" (Doob, 1979, p. 401). La exhibición de Goldstein y los agentes arrepentidos, junto con el testimonio televisivo de los actos de sabotaje, corrupción y depravación desplazan el odio de los televidentes hacia la Hermandad.

Adorno también abordó el tema, al respecto analiza: "La propaganda fascista ataca a espectros más que a opositores reales, es decir construye una imagen del judío, o del comunista, y la destroza, sin preocuparse mucho por la correspondencia de esta imagen y la realidad". (Adorno, 2005, p. 12)

Algo similar sucede en la novela ya que la imagen que construye de Goldstein -nombre que por su sonoridad y su origen indudablemente nos remite a Trotsky- y sus seguidores no son más que esto, si se corresponde con la realidad poco importa, lo fundamental es que se convierta en el blanco del odio de los miembros del partido.

Adorno asimismo se preguntaba acerca de la relación que se establecía entre el líder y sus seguidores partidarios, planteando que "este tipo de propaganda funciona como una gratificación... (...) ciertamente, 'espectáculo' es la palabra”. (Adorno, 2005, p. 13)

También el pueblo ruso vivió duros momentos bajo el régimen de lósif Stalin (1878- 1953): detenciones, purgas, encierros, torturas y ostracismo. Reminiscencias innegables resuenan en las páginas del texto que nos ocupa.

De la novela a la televisión

En el año 1997 la productora Endemol, creada por el holandés John de Mol, concibió el reality show que toma su nombre de la novela inglesa: Gran Hermano. La idea fue reunir a un grupo de personas que deben convivir en una casa, aislados, sin contacto con el exterior: ni televisión, ni teléfonos, ni Internet, lo que les imposibilita tener noticias provenientes del exterior durante su participación en el programa. Todo lo que hacen y dicen los participantes es captado por las cámaras de Big Brother. El público tiene acceso durante las veinticuatro horas a la vida de los mismos, ya que nada de lo que sucede en la casa queda oculto a ese gran ojo controlador. La convivencia comienza a demostrar lo difícil de las relaciones humanas. Muchos no resisten y se retiran o son eliminados, otros sobreviven, aunque a veces no tan heroicamente. 
Pocos son los televidentes que asocian el nombre del reality a la novela del escritor inglés. Las diferencias con el relato son más que evidentes: los participantes ingresan voluntariamente, a diferencia de los pobladores de Oceanía que son gobernados por el autoritarismo del Hermano Grande; sin embargo, no podemos dejar de preguntarnos si el rol que cumplen los televidentes que votan a los miembros que deben abandonar la casa, no juegan a ser los verdugos a la manera de O’Brien. Por supuesto que aquí no hay torturas físicas, sin embargo, las relaciones que se van desarrollando, las intrigas, los trascendidos y las relaciones de poder que se van tejiendo re-producen una (micro) sociedad colmada de excesos, ambiciones, y traiciones que desnudan las miserias del ser humano. Los participantes, voluntarios de este experimento mediático, se convierten en las mascotas de esa suerte de Cámara Gesell en la cual se puede espiar sin ser visto: cómo duermen, hablan o hasta qué hacen. El placer voyeurista del espectador televisivo le garantiza una experiencia vicaria única: una suerte de mise en abîme donde se identifica con un igual, un no-actor, un televidente más, que vive lo que él querría vivir y no puede: salir del anonimato.

Del relato al cine

Treinta y seis años más tarde que la novela viese la luz, el director Michael Radford10, traslada la novela a la pantalla cinematográfica para rendirle homenaje, al tiempo de interrogarse acerca de la vigencia de las problemáticas que le dieron origen.

Un terreno en el cual surgen día a día trabajos teóricos es el dominio de la transposición. Los posibles trasvasamientos del lenguaje literario al cinematográfico y las respuestas por las que cada director opta para determinadas problemáticas, plantean un prolífico campo de reflexión teórica. Siguiendo los conceptos desarrollados por Wolf (2001) entendemos que las operaciones realizadas para producir el guión implicaron un agregado o supresión de diálogos, sustituciones, enroques, es decir procedimientos que en su conjunto contribuyen a expresar en un nuevo lenguaje, en este caso el cinematográfico, la esencia del texto orwelliano. Contrariamente a algunas opiniones que hallamos en diversos medios, como Internet, creemos que Radford en su doble tarea de director y guionista no quedó prisionero del lenguaje literario, sino que por el contrario eligió soluciones estéticas y formales que permitieron un producto nuevo, que con recursos propios del medio restituye el clima terrorífico de la novela.

Dado que, al aproximarnos al film del realizador, pudimos notar que la novela ha sido respetada, consideramos que trazar un paralelo para marcar similitudes y diferencias entre el texto de partida y el de llegada sólo serviría para limitar nuestro abordaje. Al respecto, afirma Wolf: "Este rumbo del trabajo sobre la transposición, en realidad, se agota en sí mismo porque sólo se ocupa de detectar, en un nivel cuantitativo e impresionista, las diferencias entre texto literario y película" (Wolf, 2001, p. 22). Es por ello que declinamos este tipo de análisis en favor de centrar nuestra atención en reflexionar acerca de cómo el director cinematográfico ha utilizado los elementos propios del lenguaje del séptimo arte para plasmar el texto del autor británico.

Orwell era consciente que podría suceder que algunos lectores -especialmente los jóvenes- saltearan la lectura del "Apéndice de Neohabla" y los fragmentos del libro de Goldstein, por tal motivo llevó adelante el relato de modo tal que, aun omitiendo estas partes, pudiesen comprender la trama. El director debió considerar importante la explicación del funcionamiento del Neohabla, por ello en lugar de recurrir a la voz en off para explicarlo, optó por mantener una idea tomada de la novela: ponerlo en boca de Syme durante un almuerzo laboral. Creemos que el diálogo le quita rigidez al contenido del Apéndice en cuestión y hace más interesante la 
exposición pertinente en boca del especialista del Miniver. El desarrollo del costado oculto de Winston tendiente a ir en contra de las ideas partidarias se ve reforzado en el film a través de la elección del director. A diferencia de la novela, ni Julia ni el sirviente de O’Brien intervienen en la reunión y, aun cuando Winston lee en voz alta, para su amante -en la intimidad-, fragmentos del libro de Goldstein, ésta se queda dormida. En cuanto al lenguaje cinematográfico podemos observar que el realizador incluye la utilización permanente de paneos descriptivos y, que en muchos casos le ayudan a reemplazar el corte directo, generando un movimiento suave que le permite pasar de un plano a otro. No recurre a efectos especiales, sino a un lenguaje tributario del cine clásico.

La atmósfera del film resulta tan asfixiante como la novela. Radford concibe pantallas gigantes donde aparece la propaganda del Gran Hermano. Los tonos sepias dominan los documentales que se proyectan, lo que le aporta un plus de nostalgia y documento. La omnipresencia de las pantallas lejos de haber perdido vigencia se ha incrementado en el mundo contemporáneo, tal como podemos verlo a diario. Dicha presencia constante en el film -que estaba presenta también en la novela- no hace más que reforzar nuestra experiencia cotidiana, atravesada por la amenaza de lo inminente que se percibe.

Es indudable que la estética del film remite a la sociedad nazi: los trajes de los Niños Espías, la organización militarizada del trabajo en los ministerios, los estandartes partidarios, las ejecuciones públicas y los mitines políticos.

John Hurt y de Richard Burton fueron galardonados por su labor actoral en el film. Curiosamente Cyril Kusack quien encarna al policía del pensamiento Charrington, es el mismo actor que protagonizó al capitán Beatty en el film Fahrenheit 451 (1966), de François Truffaut. Inevitablemente ello funciona como guiño al espectador cinéfilo, que ha visto el film del director francés, puesto que en ambos encarna a la autoridad represora.

\section{Palabras de cierre}

Finalizada la Segunda Guerra algunos autores decidieron dar testimonio de lo que habían padecido. Algunos de los sobrevivientes de los campos de concentración optaron por cubrir con un manto de silencio este sufrimiento. Demasiado vivo era su dolor para darlo a conocer. Otros, optaron por no olvidar, aunque nadie desde lo racional diese credibilidad a las aberraciones que relataban. Este es el caso de Jorge Semprún, de Primo Levi y de Claude Lanzmann, entre tantos otros.

En el ámbito de la novela, autores como el que nos convoca trataron de exorcizar sus propios demonios. Fusi señala:

Al escribir 1984, Orwell quiso oponerse al totalitarismo desde la literatura. Desde una literatura que, probablemente, no era literariamente buena; pero era extraordinariamente eficaz. Más que ningún otro libro contemporáneo, 1984 despertó las conciencias de las sociedades libres y democráticas ante el horror y el peligro del totalitarismo y de la mentalidad totalitaria. (Fusi, 2004, p. 93)

Coincido con este autor en la mayoría de los aspectos, ya que en el momento de su aparición, este libro provocó profundas reflexiones en una parte de la sociedad. La lectura y relectura de la obra nos demuestra que no ha pasado de moda, que presenta aún una vigencia abrumadora. Al comparar la relación entre los medios de 
comunicación y el poder -un aspecto fundamental tanto en el texto literario con su incidencia en el audiovisualsostenemos que, así como la vida de los ciudadanos en la novela es totalmente controlada por los agentes de poder, esto vuelve a quedar en evidencia en la película del mismo nombre filmada en el año 1984, situación que también se extiende hasta hoy. Muy a nuestro pesar, los totalitarismos continúan vigentes en la actualidad: nacen, se desarrollan y pese a que parecen extinguirse, nada más alejado. Creemos haber aniquilado al mal, pero éste se oculta. Vive agazapado en las sombras. Aguarda el momento preciso. Espía sobre el hombro de los gobernantes, esperando a aquel que se deje deslumbrar por su canto de sirena. Aquel cuya ambición y escrúpulos le den cabida. Aquel dispuesto a venderle su alma al diablo y que aplaque su sed de sangre, de miles de inocentes.

\section{Notas}

\section{Partido Obrero de Unificación Marxista.}

2. Juego de estrategia de guerra donde los jugadores se disputan los países del mundo.

3. "En su forma clásica, la utopía es la construcción de una sociedad ideal, pensada como perfecta o por lo menos alternativa". (Capanna, 2007, p. 183)

4. Es decir, el "mal lugar", ya que la visión pesimista del mundo que describen es la nota dominante de los relatos en cuestión.

\section{INSOC o Socialismo Inglés.}

6. Combinación, en una misma estructura sintáctica, de dos palabras o expresiones de significado opuesto que originan un nuevo sentido, como en un silencio atronador. Diccionario de la real Academia Española http://dle.rae.es/?id=RNRzJK5 Recuperado el 08/12/16.

7. Si bien en la traducción consultada figura mencionado como Hermano Grande, para nuestro desarrollo adoptaremos una versión más coloquial, respondiendo al uso que le damos en castellano: Gran Hermano.

8. "[...] Que el preso esté sin cesar observado por un vigilante: demasiado poco, porque lo esencial es que se sepa vigilado; demasiado, porque no tiene necesidad de serlo efectivamente. Para ello Bentham ha sentado el principio de que el poder debía ser visible e inverificable. Visible: el detenido tendrá sin cesar ante los ojos la elevada silueta de la torre central de donde es espiado. Inverificable: el detenido no debe saber jamás si en aquel momento se le mira; pero debe estar seguro de que siempre puede ser mirado". (Foucault, 2004, p. 63)

9. "Quien ha leído o visto Fahrenheit 451 de Ray Bradbury ha podido hacerse una idea de lo que significaría verse obligado a vivir en un mundo sin libros, y qué valor asumiría en él el recuerdo de los libros” (Levi, 2011). La trilogía de Auschwitz. Si esto es un hombre. La Tregua. Los hundidos y los salvados. Madrid: El Aleph, p. 592.

10. Director y guionista cinematográfico, nacido en 1946 en Nueva Delhi, India. Licenciado en la National Film School. Se desempeñó como documentalista para la BBC. Realizador y guionista de 1984 (1984), II postino (1994), El mercader de Venecia (2004), Un plan brillante (2007), entre otros. 


\section{Bibliografía}

Adorno, T. W. (2005). Ensayo sobre la propaganda fascista. Psicoanálisis del antisemitismo. Buenos Aires: Paradiso.

Báez, F. (2005). Historia universal de la destrucción de los libros. De las tablillas sumerias a la guerra de Irak. Buenos Aires: Sudamericana.

Bauzá, H. F. (2005). Qué es un mito. Una aproximación a la mitología clásica. Buenos Aires: Fondo de Cultura Económica. Capanna, P. (2007). Ciencia Ficción. Utopía y mercado. Buenos Aires: Cántaro.

Di Tella, T.; Chumbita, H.; Gamba, S.; Gajardo, P. Diccionario de Ciencias Sociales y Políticas. Buenos Aires: EMECÉ.

Doob, L. W., “Goebbels y sus principios propagandísticos" en Moragas, M. (ed.) (1979). Sociología de la Comunicación de Masas. Barcelona: Gustavo Gili, pp. 381-404.

Foucault, M. (1993). Genealogía del racismo. Montevideo: Caronte Ensayos. (2004). Vigilar y castigar. Nacimiento de la prisión. Buenos Aires: Siglo Veintiuno Editores Argentina.

Fusi, J. P. (2004). El malestar de la modernidad. Cuatro estudios sobre historia y cultura. Madrid: Biblioteca Nueva.

Germani, G. (2003). Autoritarismo, fascismo y populismo nacional. Buenos Aires: Universidad Torcuato Di Tella.

Gruber, M., "La temperatura en la que arden las ideas" en Babino, M. E. (Comp.). (2011). La literatura en el teatro y el cine. Buenos Aires: Nobuko/ FADU, pp. 57-71.

Levi, P. (2011). Los hundidos y los salvados en La trilogía de Auschwitz. Madrid: El Aleph.

Manguel, A. (2007). La biblioteca de noche. Bogotá: Norma.

Orwell, G. (1950). Mil novecientos ochenta y cuatro. Versión Arturo Bray. Buenos Aires: Guillermo Kraft.

Semprún, J. (1995). La escritura o la vida. Barcelona: Tusquets.

Tafalla, M. (2003). Theodor W. Adorno. Una filosofía de la memoria. Barcelona: Herder.

Wolf, S. (2001). Cine / Literatura. Ritos de pasaje. Buenos Aires: Paidós.

Abstract: World War II, the Shoah, the Gulag, Hiroshima and Nagasaki, constitute a long list of ignominious facts that have set fire to humanity. Not surprisingly, lucid intellectuals and artists raised their voices to point out the failure of the ancient rational paradigms that underpinned modernism: if that rationalism had led to failure, it was 
necessary to look for new structures that would help to overcome the past. Thus they saw a hope in the resurgence of the myth.

With the postwar period, a stage known as the Cold War was opened, which was characterized, among other things, by the dizzying growth of communication, as well as the development of all kinds of control mechanisms and gadgets ranging from microfilms and microphones, to cameras. The USSR and the US, with their secret services, played a war of nerves where everything seemed valid: serum of truth, various tortures and brainwashing, among others, were terms that moved from the political field to literature, cinema and theater. These elements contributed to the imagination of the artists, who in cases such as the one we analyzed, placed criticism on the world around them in a dystopian future.

The present work aims to analyze some aspects of George Orwell 's novel 1984 (1948), exploring the lines of hermeneutic depth that gave life to its characters and conflicts, and then to approach the homonymous cinematographic transposition.

In comparing the relationship between the media and power -a fundamental aspect both in the literary text and its impact on the audiovisual- we maintain that just as the life of the citizens in the novel is totally controlled by the agents of power, this is again evident in the film of the same name filmed in 1984, a situation that also extends today. Much to our regret, totalitarianisms continue to prevail today.

Key words: Cold War - totalitarianism - Orwell - 1984 - Film representations.

Resumo: A II Guerra Mundial, a Shoah, o Gulag, Hiroshima e Nagasaki, constituem uma longa lista de fatos ignominiosos que marcaram a fogo à humanidade. Por isso, lúcidos intelectuais e artistas marcaram o fracasso dos antigos paradigmas racionais que sustentaram o modernismo: se esse racionalismo tinha levado ao fracasso, havia que procurar novas estruturas que ajudassem a superar o passado. Desse modo, divisaram uma esperança no ressurgimento do mito.

Com o pós-guerra, abriu-se uma etapa conhecida como a Guerra Fria, que se caracterizou por o crescimento rápido das comunicações, e por o desenvolvimento de todo tipo de mecanismos de controle e gadgets que abarcaram desde microfilmes e microfones até câmaras. A URSS e os EEUU, com seus serviços segredos, brincaram uma guerra de nervos onde tudo parecia válido: soro da verdade, torturas, lavado de cérebro, entre outros, foram termos que se transladaram desde o campo político até a literatura, o cinema e o teatro. Esses elementos contribuíram à desenvolver a imaginação dos artistas, que em casos como o que se analisa situaram num futuro distópico as críticas ao mundo que lhes rodeava.

Este trabalho analisa aspectos da novela 1984 de George Orwell (1948) explorando as linhas de profundidade hermenêutica que deram vida aos personagens e conflitos, para depois abordar a transposição cinematográfica homônima. Ao comparar a relação entre os meios de comunicação e o poder, dizemos que assim como a vida dos cidadãos na novela é controlada pelos agentes do poder, o filme feito em 1984 mostra a mesma questão, situação que até hoje pode ser evidenciada, já que os totalitarismos estão ainda vigentes.

Palavras chave: Guerra Fria - totalitarismos - Orwell - 1984 - representações fílmicas. 
Medios y poder: 1984 fue publicado de la página 109 a página122 en Cuadernos del Centro de Estudios de Diseño y Comunicación № 68 